\title{
PREVALENCE OF BLEEDING GUMS;
}

IN ASSOCIATION WITH ORAL HEALTH PRACTICES IN PATIENTS VISITING NISHTAR INSTITUTE OF DENTISTRY, MULTAN, PAKISTAN

1. BSc, BDS (Silver Medalist) Past House Officer Nishtar Institute of Dentistry, Multan. 2. MBBS

House Officer

DHQ Teaching Hospital, Sargodha

Correspondence Address:

Ruksana Akram

Address: Near Lari Adda Musa Khel

District \& Tehsil Mian Wali.

Punjab, Pakistan,

rukhsar_niazi@yahoo.com

Article received on:

08/08/2017

Accepted for publication:

$15 / 10 / 2017$

Received after proof reading:

$29 / 11 / 2017$

\section{Ruksana Akram ${ }^{1}$, Mian Azizullah Khan²}

ABSTRACT... Objectives: To evaluate the prevalence of bleeding gums in association with oral health practices. Study Design: Descriptive cross sectional. Setting: Main Diagnostic Department NID, Multan, Pakistan. Materials and Methods: Period: $1^{\text {st }}$ January 2017 to $31^{\text {st }}$ March 2017. 1000 patients of either gender or age who came to main diagnostic department, NID, Multan, Pakistan for treatment purpose. A Questionnaire was designed. After getting consent, questions were asked and clinical examination was done to assess the frequency, accuracy of brushing technique, prevalence of calculus deposition and bleeding gums. Patients were asked about the devices they used for oral Hygiene practices. Result: Result showed that out of total sample $92.3 \%$ of patients were Brushing. $90 \%$ of them were using improper Brushing technique. $81.4 \%$ showed calculus deposits and $40.6 \%$ bleeding gums. Higher prevalence of bleeding gums and calculus deposits were in 26-30years old age groups and 21-25 years old individuals respectively. $92 \%$ of the patient with bleeding gums had associated calculus.98\% of patients with bleeding gums had improper brushing technique.98\% of the patients with calculus had improper brushing technique.1.2\% of the patients were flossing. Conclusion: Improper brushing technique is the main factor for calculus deposits that is the leading cause for bleeding gums.

Key words: $\quad$ Bleeding Gums; Calculus Deposition; Proper Way of brushing; Flossing, Age Groups; Gender; Frequency and Timings of Brushing.

Article Citation: Akram R, Khan MA. Prevalence of bleeding gums; In association with oral health practices in patients visiting Nishtar Institute of Dentistry, Multan, Pakistan. Professional Med J 2017;24(12):1904-1908.

DOI:10.17957/TPMJ/17.4233

\section{INTRODUCTION}

Oral health is considered as an integral part of general health which is achieved by good oral hygiene. ${ }^{1-2}$ Oral diseases qualify as one of the foremost public health dilemma owing to their higher prevalence in general population. ${ }^{3}$

Poor oral hygiene is the main leading cause for the development of oral diseases which heavily affect general health. ${ }^{4}$ Other etiological factors include age, gender, genetic predispositions, certain systemic conditions like hormonal changes, puberty, pregnancy, menopause and diabetes mellitus. ${ }^{5}$

Poor oral health may initiate and potentiate certain systemic problems like stress, cardiovascular diseases, diabetes mellitus, rheumatoid arthritis and low birth weight babies etc. ${ }^{6-8}$ Most common oral disease is gingivitis and its primary etiological factor is plaque and calculus deposition leading to bleeding gums. ${ }^{9-14}$ Three out of four people may suffer from gum diseases during their life time..$^{15}$ Gingivitis represents as red, painful, swollen inflamed bleeding gums. If gingivitis is left untreated it can lead to periodontal problems. ${ }^{16}$ Bleeding on probing and bleeding on brushing now have become a gold standard measure of gingivitis. ${ }^{17}$ Bleeding gums and other oral diseases are more common in people with low socio-economic status having poor oral hygiene and unawareness about oral health. ${ }^{18}$

Bleeding gums can be minimized by providing oral health education to the general population. ${ }^{19}$ Self care is the best care for everything. Internal motivation is the main factor to maintain oral health and prevent plaque and calculus..$^{20}$ Cleaning teeth with brush is common practice in Pakistan however floss, miswak, dandasa and 
manjan are also in use for the same purpose. ${ }^{21}$ A national health survey in Pakistan showed that $36 \%$ of Pakistani population cleaned their teeth once a day and $54 \%$ cleaned their teeth on alternative days/ weekly or monthly. ${ }^{22}$ Although there are different mechanical and chemical methods recommended for the improvement of oral health but tooth brush and floss is widely accepted primary method for removing plaque and calculus. ${ }^{23}$ Tooth brush removes plaque from buccal and lingual surfaces while dental floss is use for interdental areas. ${ }^{24}$ Effective plaque control can facilitate improvement in gingival and periodontal health and prevents tooth damage. ${ }^{25}$ Brushing efficacy depends upon different factors like type of brush either hard or soft, effective technique, time of brush and frequency. ${ }^{26}$ Keeping in view the importance of good oral hygiene by proper way of brushing and flossing, the present study was carried out to evaluate the prevalence of bleeding gums in association with awareness regarding oral hygiene measures.

\section{MATERIALS AND METHODS}

This descriptive cross sectional study was carried out from $1^{\text {st }}$ January to $31^{\text {st }}$ March 2017 on 1000 patients of either gender or gender who came to main diagnostic department NID, Multan, Pakistan for treatment. A questionnaire was used and approval was taken from concerned authorities of NID, Multan, Pakistan regarding this study. Getting consent, demographic details (age, gender, address, occupation, marital status and medical history) were asked from the patients. Patients were asked about devices they used for oral hygiene practices, its time and frequency. For the assessment of proper way of brushing ${ }^{26}$, patients were asked to suppose their index finger as tooth brush then how would they brush their teeth. Patients were asked about the use of floss and bleeding on brushing. After getting complete information regarding oral hygiene practices, clinical examination was done to check the presence of calculus and bleeding on probing. The observations were entered in the perform. The data was analyzed by using SPSS version 20 .

\section{RESULTS}

Out of 1000 patients, $40.6 \%$ (male $17.7 \%$ Female $22.9 \%$ ) had bleeding gums. Out oftotal sample $44 \%$ of males and $56 \%$ of females were suffered from bleeding gums. Out of 487 male patients $36.3 \%$ were suffering from bleeding gums compared to $45 \%$ of females out of total sample of 513 females (Table-I). Out of total sample $814(81.4 \%)$ had calculus deposits, $496(49.6 \%)$ of them were males and 503(50.3\%) were females. Out of 487 male patients $82.9 \%$ had calculus deposits as compared to $79.9 \%$ females out of total sample of 513 females (Table-II). Out of total participants 92.3\% were using brush as a cleansing device for their teeth (Table-III) but $90 \%$ of the patients were using improper brushing technique. It was found that maximum of the individuals were brushed their teeth at morning (56.7) (Table-IV) and once a day (55.5\%) (Table-V). $98 \%$ of the patients with calculus had improper brushing technique (Table-VI) 98\% of patients with bleeding gums had improper brushing technique. (TableVII). It was found that $92 \%$ of the patients with bleeding gums had associated calculus. 1.2\% of the patients were flossing. It was found that higher prevalence of bleeding gums and calculus deposits were in 26-30 years old age groups and 21-25 years old individuals respectively. Below 10 years old and above 50 years old individuals did not have any significant percentage of bleeding gums as compare to calculus (Table-VIII).

\begin{tabular}{|l|c|c|c|}
\hline \multirow{2}{*}{ Gender } & \multicolumn{2}{|c|}{ Bleeding Gums } & Total \\
\cline { 2 - 4 } & Yes & No & 487 \\
\hline Male & 177 & 310 & 513 \\
\hline Female & 229 & 284 & 1000 \\
\hline Grand Total: & 406 & 594 & cross tabulation of bleeding \\
\hline Table-I. Gender wise & \\
\hline
\end{tabular}

\begin{tabular}{|l|c|c|c|}
\hline \multirow{2}{*}{ Gender } & \multicolumn{2}{|c|}{ Calculus Deposits } & \multirow{2}{*}{ Total } \\
\cline { 2 - 4 } & Yes & No & \\
\hline Male & 404 & 83 & 487 \\
\hline Female & 410 & 103 & 513 \\
\hline Grand Total: & 814 & 186 & 1000 \\
\hline \multicolumn{2}{|c|}{ Table-Il. Gender wise cross tabulation of calculus } \\
deposits
\end{tabular}




\begin{tabular}{|l|c|c|}
\hline \multicolumn{1}{|c|}{ Device } & Frequency & Percent\% \\
\hline Brush & 856 & 85.6 \\
\hline Brush + Manjan & 3 & 0.3 \\
\hline Miswak & 39 & 3.9 \\
\hline Dandasa & 10 & 1.0 \\
\hline Manjan & 12 & 1.2 \\
\hline Brush \& Miswak & 55 & 5.5 \\
\hline Brush + Miswak + Dandasa & 3 & 0.3 \\
\hline Brush + Dandasa & 6 & 0.6 \\
\hline Miswak + Dandasa & 5 & 0.5 \\
\hline None & 11 & 1.1 \\
\hline Total: & 1000 & 100.0 \\
\hline
\end{tabular}

Table-III. Devices used for cleaning teeth

\begin{tabular}{|l|c|c|}
\hline & Frequency & Percent $\%$ \\
\hline Morning & 567 & 56.7 \\
\hline Evening & 48 & 4.8 \\
\hline After noon & 65 & 6.5 \\
\hline Morning \& evening & 308 & 30.8 \\
\hline None & 12 & 1.2 \\
\hline
\end{tabular}

Table-IV. Timings of Brushing

\begin{tabular}{|l|c|c|}
\hline & Frequency & Percent $\%$ \\
\hline 1 time & 555 & 55.5 \\
\hline 2 times & 297 & 29.7 \\
\hline More than 2 times & 9 & 0.9 \\
\hline Off \& on & 127 & 12.7 \\
\hline None & 12 & 1.2 \\
\hline Total: & 1000 & 100.0 \\
\hline
\end{tabular}

Table-V. Frequency of teeth cleaning

\begin{tabular}{|l|c|c|c|}
\hline $\begin{array}{c}\text { Proper } \\
\text { Brushing }\end{array}$ & Yes & No & Total \\
\hline Yes & 16 & 7 & 23 \\
\hline No & 798 & 179 & 977 \\
\hline Grand Total: & 814 & 186 & 1000 \\
\hline Table-VI. Cross tabulation between proper brushing\& \\
\begin{tabular}{c} 
calculus \\
\hline
\end{tabular}
\end{tabular}

\begin{tabular}{|l|c|c|c|}
\hline $\begin{array}{c}\text { Proper } \\
\text { Brushing }\end{array}$ & \multicolumn{2}{|c|}{ Bleeding Gums } & Total \\
\hline Yes & Yes & No & 23 \\
\hline No & 5 & 18 & 977 \\
\hline Grand Total: & 401 & 576 & 1000 \\
\hline Table-VII. Proper brushing \& Bleeding gums Cross \\
\multicolumn{2}{|c|}{\begin{tabular}{c} 
tubulation \\
\hline
\end{tabular}} \\
\hline
\end{tabular}

\begin{tabular}{|c|c|c|}
\hline Age Groups & Calculus & Bleeding gums \\
\hline $1-5$ & $0(0.0 \%)$ & $1(0.2 \%)$ \\
\hline $6-10$ & $13(1.6 \%)$ & $11(2.7 \%)$ \\
\hline $11-15$ & $36(4.4 \%)$ & $32(7.9 \%)$ \\
\hline $16-20$ & $79(9.7 \%)$ & $43(10.6 \%)$ \\
\hline $21-25$ & $127(15.6 \%)$ & $63(15.5 \%)$ \\
\hline $26-30$ & $125(15.4 \%)$ & $69(17 \%)$ \\
\hline $31-35$ & $93(11.4 \%)$ & $50(12.3 \%)$ \\
\hline $36-40$ & $115(14.1 \%)$ & $58(14.3 \%)$ \\
\hline $41-45$ & $71(8.7 \%)$ & $31(7.6 \%)$ \\
\hline $46-50$ & $55(6.8 \%)$ & $19(4.7 \%)$ \\
\hline $51-55$ & $35(4.3 \%)$ & $11(2.7 \%)$ \\
\hline $56-60$ & $23(2.8 \%)$ & $5(1.2 \%)$ \\
\hline $61-65$ & $22(2.7 \%)$ & $8(2.0 \%)$ \\
\hline $66-70$ & $14(1.7 \%)$ & $4(1.0 \%)$ \\
\hline $71-75$ & $6(0.7 \%)$ & $1(0.2 \%)$ \\
\hline Total & $814(100.0)$ & $406(100.0)$ \\
\hline Table-VIII. Frequency $\&$ percentage of calculus \& \\
\hline Bleeding gums among different Age groups \\
\hline
\end{tabular}

$P$ Value for bleeding gums $=0.000$

$\mathrm{P}$ Value for calculus $=0.000$

\section{DISCUSSION}

Present study showed that $92 \%$ patients with bleeding gums had associated calculus deposits. These findings were not consistent with the findings of Sarah Ali et $\mathrm{Al}^{27}$ and Gilani Syed Imran et Al. ${ }^{28}$ These results showed that females suffered more from bleeding gums and males had more calculus deposits. The results of this study are in contrast to a study of Chinese population which showed that there are no difference between gender based distribution of bleeding gums. ${ }^{29}$ Another American study proved that males were affected more than females. ${ }^{30}$ The results of present study showed that age and gender based distribution had significant role in bleeding gums and calculus deposits. $55.5 \%$ of patients were used to brush their teeth once a time \& $29.9 \%$ twice a day which was not consistent with the findings of Parveen $\mathrm{N}$ et Al where it was $46.2 \%$ \& $38.9 \%$ respectively. ${ }^{31}$ Practice of dental floss (1.2\%) was found to be less which was similar to study by Al- omiri et $\mathrm{Al}^{32}$ and different from a study conducted in Nishtar institute of dentistry Multan, Pakistan by Parveen $\mathrm{N}$ et $\mathrm{Al}^{31}$ where the use of dental floss was $15.4 \%$. In present study $92.3 \%$ patients were brushing. The findings were similar to a Japanese ${ }^{33}$ study and Normark $S$ et 
Al. ${ }^{34} 8.6 \%$ of the patients using improper brushing technique did not develop calculus deposits because of other oral hygiene practices e.g. increased frequency of brushing, flossing, mouth rinses and high socio-economic status. Bleeding gums in $40.6 \%$ of the population was persistent with certain factors such as female gender, 2130 years old age group and low socio-economic status.

\section{CONCLUSION}

Improper brushing technique is the main factor for calculus deposits that is the leading cause for bleeding gums.

\section{RECOMMENDATION}

All the patients coming to the dentist should not only be educated about proper way of brushing to improve oral health but also guided them about other additional oral hygiene practices like flossing, mouth rinses and early treatment of any dental or periodontal diseases.

\section{ACKNOWLEDGEMENTS}

I am thankful to Nishtar Institute of Dentistry Multan. Pakistan especially Dr Muhammad Pervaiz lqbal Phd, Head of Conservative dentistry department NID Multan Pakistan for his supervision and my colleagues dr Saima Asghar and dr momina Tahir for their worthy suggestions.

\section{Copyright(C) 15 Oct, 2017.}

\section{REFERENCES}

1. Stella Y. Kwan L, Petersen PE, Pine CM, Borutta A. Health-promoting schools: an opportunity for oral health promotion. 2005; 83 (9): 677-85.

2. Al-Ansari J, Honkata E, Honkata S. Oral health knowledge and behavior among male health sciences college students in Kuwait. BMC Oral Health 2003; 3(1):2.

3. Butt AM, Ahmed B, Parveen N and Yazdanie N. Oral Health Related Quality of life in complete dentures. Pak Oral Dent J 2009; 29(2):397-402.

4. Chrysanthakopoulos NA. Prevalence of gingivitis and associated factors in 13-16-year-old adolescents in Greece. Eur J Gen Dent 2016; 5:58-64.

5. Kazemnejad A, Zayeri F, Rokn AR, Kharazifard MJ. Prevalence and risk indicators of periodontal disease among high-school students in Tehran. East Mediterr Health J 2008; 14:119-25.

6. Al-Khabbaz AK, Al-Shammari KF, Al-Saleh NA. Knowledge about the association between periodontal diseases and diabetes mellitus: contrasting dentist and physicians. J Periodontol. 2011; 82(3):360-6.

7. Rakchanok N, Amporn D, Yoshida Y, Harun-Or-Rashid $\mathrm{M}$, Sakamoto J. Dental caries and gingivitis among pregnant and non-pregnant women in Chiang Mai, Thailand. Nagoya J Med Sci. 2010; 72(1-2):43-50.

8. Gangadhar V, Ramesh A, Thomas B. Correlation between leptin and the health of the gingiva: $A$ predictor of medical risk. Indian J Dent Res. 2011; 22(4):537-41.

9. Iqbal M pervaiz, Siddiqui M. Ismail Kausar Lubna, Iqbal M. Javed. Difference in Plaque Removal from Buccal \& Lingual Surfaces of Teeth by Manual Brushing. P J M H S 2015:9(3):986-988

10. Albandar JM, Buischi YA, Mayer MP, Axelsson $P$ (1994) Long-Term Effect of Two Preventive Programs on the Incidence of Plaque and Gingivitis in Adolescents. J Periodontol 65: 605-610.

11. Socransky SS, Haffajee AD (1992) The Bacterial Etiology of Destructive Periodontal Disease: Current Concepts. J Periodontol 63: 322-331.

12. American Academy of Periodontology (1999) The pathogenesis of periodontal diseases. J Periodontol 70: 457-470.

13. Page RC (1986) Gingivitis. J ClinPeriodontol 13: 345359.

14. Ranney RR, Debski BF, Tew JG (1981) Pathogenesis of gingivitis and periodontal disease in children and young adults. Pediatr Dent 3: 89-100.

15. Hassija J, Sridhar N (2014) Healthy Lifestyle for Healthy Gums. Dentistry 4:235. doi: 10.4172/21611122.1000235

16. Zimmer S, Bizhang $M$, Seemann $R$, Barthel $C R$ (2001) [Effective of preventive programs on oral hygiene of adults and school children]. Gesundheitswesen 63: 98-101.

17. Farina R, Scapoli C, Carrieri A, Guarnelli ME, Trombelli L. Prevalence of bleeding on probing: a cohort study in a specialist periodontal clinic. Quintessence Int. 2011; 42(1):57-68.

18. Harikiran AG, Pallavi SK, Hariprakash S, Ashutosh and Nagesh KS. Oral Health related KAP among 11 to 
12-year-old school children in a government-aided missionary school of Bangalore city. Indian J Dent Res 2008; 19:236-42.

19. Kegeles SS. Some motives for seeking preventive dental care. J Am Dent Assoc 1963; 67:110-118.

20. Memon $A B$, Memon $M Y$ Khatoon $S$ \& llyas $M$. Plaque score and gingival health status among 6-12 years old children In Hyderabad Division PodJ 2015:35(3):485-488

21. Bangash, Rehana Yasmeen; Khan, Abid Ullah; Tariq, Khalid Mehmood; Rasheed, Dil. Evaluation of tooth brushing technique and oral hygiene knowledge at afid, Rawalpindi. PODJ 2012;32(1):124127

22. Lazarescu D, Boccaneala S, Illiescu A, De Boever JA. Efficacy of plaque removal and learning effect of a powered and a manual toothbrush. J Clin Periodontol 2003; 30:726-31.

23. Astrøm AN, Samdal O. Time trends in oral health behaviors among Norwegian adolescents: 1985-97. Acta Odontologica Scandinavica. 2001; 59(4): 193-200. 12.

24. Walsh MM. Effect of school-based dental health education on knowledge, attitudes and behavior of adolescents in San Francisco. Community Dent Oral Epidemiol, 1985; 13(3): 143-7.

25. Nikiforuk G. Understanding dental caries, prevention basic and clinical aspect, New York, Karger publication; 1985.

26. Yousaf A, Aman N, Manzoor Ahmed,
Comparison of powered and manual toothbrushes in removal of plaque PodJ 2012 32(1):120-123.

27. Ali Sarah, Nasir Nomaan, Masood Abida, Prevalence of gingivitis in Patients visiting Islamic International Dental Hospital, Ann. Pak. Inst. Med. Sci. 2012; 8(2): 150-152.

28. Gilani Syed Imran, Tanwir Farzeen, Afridi Saira, Oral health assessment and barriers to seek care in internally displaced persons from Bajaur agency, Pakistan. Podj 2012:32(1):115-9.

29. Zhang J, Xuan D, Fan W, Zhang X, Dibart S, De Vizio $W$, et al. Severity and prevalence of plaque-induced gingivitis in the Chinese population. Compend Contin Educ Dent. 2010; 31(8):624-9.

30. Li Y, Lee S, Hujoel P, Su M, Zhang W, Kim J, Zhang YP, DeVizio W. Prevalence and severity of gingivitis in American adults. Am J Dent. 2010; 23(1):9-13.

31. Parveen nagina, Ahmad B, Bari A. Oro-dental health: awareness and practices. JUMDC 2011 2(2):5-8.

32. Al-Omiri MK, Al-Wahadni AM and Saeed KN. Oral health attitudes, knowledge, and behavior among school children in North Jordan. J Dent Educ 2006; 70:179-87.

33. Health Policy Bureau Ministry of Health and Welfare, Japan. Report on the survey of dental disease. Oral Health Association, Tokyo 1995, pp. 156-158.

34. Normark S, Mosha HJ. Knowledge, practices and dental health among rural Tanzania children. African Dent J 1989; 3:24-33.

\begin{tabular}{|c|c|c|c|}
\hline \multicolumn{4}{|c|}{ AUTHORSHIP AND CONTRIBUTION DECLARATION } \\
\hline Sr. \# & Author-s Full Name & Contribution to the paper & Author $=\mathbf{s}$ Signature \\
\hline $\begin{array}{l}1 \\
2\end{array}$ & $\begin{array}{l}\text { Ruksana Akram } \\
\text { Mian Azizullah Khan }\end{array}$ & $\begin{array}{l}\text { Data collection, Entry, Paper } \\
\text { written } \\
\text { Statistical analysis }\end{array}$ & 2) \\
\hline
\end{tabular}

